\title{
ASPERGELLUS NIGER COMO PRODUTOR DE ENZIMAS CELULOLITICAS A PARTIR FARELO DE CACAU (THEOBROMA CACAO)
}

\author{
T.C. dos Santos ${ }^{1}$, T.J.O. Rocha ${ }^{1 *}$, A.C. Oliveira ${ }^{1}$, G. Abreu Filho ${ }^{1 * *}$, M. Franco ${ }^{2}$
}

${ }^{1}$ Universidade Estadual do Sudoeste da Bahia, Centro de Desenvolvimento e Difusão a Tecnologia, Laboratório de Resíduos Agroindustriais, Praça Primavera, 40, CEP 457000-000, Itapetinga, BA, Brasil. E-mail: marcelofranco@pq.cnpq.br

\section{RESUMO}

\begin{abstract}
O objetivo deste trabalho foi estudar a aplicação do fungo Aspergillus niger como produtor das enzimas celulolíticas CMCase, FPase e Xilanase, através da fermentação em estado sólido de cacau (Theobroma cacao). Avaliaram-se o efeito do tempo de fermentação (24,72, e 120 horas) e da atividade de água $(0,963 ; 0,976$ e 0,983$)$ sobre a produção das enzimas. As fermentações foram realizadas a $30^{\circ} \mathrm{C}$ em estufa bacteriológica. A otimização das condições ideais para produção de enzimas foi realizada a partir da Metodologia de Superfície de Resposta (MSR). Estatisticamente, as melhores atividades para a CMCase obtidas foram 14,18 U/mL em 0,972 aw e 70,07 horas de fermentação, para a FPase $7,51 \mathrm{U} / \mathrm{mL} 0,974$ aw 80,56 horas e para a Xilanase foi 11,86 U/mL 0,971 aw e 64,24 horas.
\end{abstract}

PALAVRAS-CHAVE: Superfície de resposta, fungos filamentosos, produção enzimática.

\section{ABSTRACT}

ASPERGELLUS NIGER AS A PRODUCER OF CELLULOLYTIC ENZYMES FROM COCOA (THEOBROMA CACAO) MEAL. The aim of this work was to study the application of the fungus Aspergillus niger as a producer of the cellulolytic enzymes CMCase, FPase and Xylanase by solid-state fermentation of cocoa (Theobroma cacao). We evaluated the effect of fermentation time $(24,72$, and 120 hours) and water activity $(0.963,0.976$ and 0.983$)$ on the production of enzymes. Fermentations were performed at $30^{\circ} \mathrm{C}$ in a bacteriological incubator. The optimization of ideal conditions for enzyme production was carried out using the response surface methodology (RSM). Statistically, the best activity obtained for CMCase was $14.18 \mathrm{U} / \mathrm{mL}$ at $\mathrm{a}_{\mathrm{w}} 0.972$ and 70.07 hours fermentation, for FPase it was $7.51 \mathrm{U} / \mathrm{mL}$ at $0.974 \mathrm{a}_{\mathrm{w}}$ and 80.56 hours, while for Xylanase was 11.86 $\mathrm{U} / \mathrm{mL}$ at $\mathrm{a}_{\mathrm{w}} 0.971$ and 64.24 hours.

KEY WORDS: Response surface, filamentous fungi, enzyme production.

\section{INTRODUÇÃO}

A denominação fungos filamentosos abrange os fungos formados por hifas, uni ou pluricelulares, que formam revestimentos esbranquiçados ou coloridos, sobre o substrato onde crescem. São descritas mais de 100.000 espécies, distribuídas em aproximadamente 3.000 gêneros (MENEZES, 2006). Os fungos filamentosos constituem, atualmente, materiais biológicos ideais para produção de substâncias de interesse biotecnológico, possuindo crescimento rápido e baixo custo de cultivo, possibilitando cultivos sob condições controladas em laboratório (SIMÕEs; TAUKTORNISIELO, 2005).
O Aspergillus niger é onipresente no solo possuindo importante função na decomposição de matéria orgânica no meio ambiente. De fácil manipulação, este fungo é capaz de sintetizar uma ampla faixa de enzimas lignocelulolíticas a partir de uma grande variedade de matérias-primas de baixo custo (SLIVINSKI, 2007). As formas mutantes dessa espécie também são bastante utilizadas, já que o rendimento de um processo enzimático produtivo pode ser melhorado através da seleção de mutantes que sejam mais resistentes à repressão catabólica e que sintetizem maiores quantidades de enzima sem a presença de um indutor (Menezes, 2006).

${ }^{2}$ Universidade Estadual de Santa Cruz, Departamento de Ciências Exatas e Tecnológicas, Ilhéus, BA, Brasil.

*Bolsista de iniciação tecnológica - IT/CNPq.

**Bolsista de iniciação científica. 
Na fermentação em estado sólido (FES) os fungos apresentam-se como micro-organismos mais promissores, pois o desenvolvimento das hifas permite que eles colonizem e penetrem no substrato e na região porosa entre as partículas do substrato (SILVEIRA; FURLONG, 2007). As enzimas industriais são grandes representantes dos processos biotecnológicos. $\mathrm{O}$ setor de produção de enzimas apresenta muitas iniciativas de pesquisa e desenvolvimento, resultando na produção de diversos produtos novos e no melhoramento dos processos e do desempenho dos produtos já existentes no mercado. No entanto, o custo elevado de uma enzima é um dos principais fatores que determinam a economia de um processo. Reduzir os custos de produção é fundamental para aplicações industriais (PARK et al., 2002).

De acordo com ARANTeS; SAdDLER (2010), a hidrólise enzimática da celulose é catalisada por enzimas altamente específicas que são chamadas de celulases; na realidade, trata-se de um complexo enzimático composto por pelo menos três grandes grupos de celulases: endoglucanases (EC 3.2.1.4), que clivam randomicamente as ligações internas da região amorfa, liberando oligossacarídeos com terminações redutoras e não redutoras livres; exoglucanases (EC 3.2.1.91), subdivididas em celobiohidrolases, que são responsáveis pela hidrólise dos terminais redutores e não redutores; xilanases (EC 3.2.1.8), enzimas responsáveis pela hidrólise da xilana, que é o principal polissacarídeo constituinte das hemiceluloses (YANG et al., 2006).

O grão do cacau é utilizado para fabricação de chocolate e, durante o processamento, gera uma grande quantidade de resíduo denominado farelo de cacau. Considerando-se que o farelo de cacau representa $10 \%$ da produção das amêndoas secas de cacau que foi estimada em $218.000 \mathrm{t}$, no ano de 2009, estima-se que a produção brasileira desse resíduo, neste ano, no Brasil, foi de 21.800 t, (NETO et al., 2008).

A proporção aproveitável de subprodutos e resíduos do cacau é bastante expressiva, pois menos de $8 \%$ do peso do fruto do cacaueiro, em estado normal de maturação, são usados pela indústria beneficiadora. Em geral, um fruto com peso médio de 500 g é constituído de $80 \%$ da casca do fruto e $20 \%$ de semente, na qual estão presentes o grão seco (10\%), a amêndoa $(8 \%)$, a testa $(1,5 \%)$ e outros constituintes $(0,5 \%)$ do total do fruto (PIREs et al., 2005).

O objetivo deste trabalho foi estudar o efeito da atividade de água e do tempo de fermentação sobre a produção das seguintes enzimas: CMCase (endoglucanase), FPase (complexo endoglucanase e exoglucanase) e Xilanase, através da fermentação do farelo de cacau (Theobroma cacao L.) e o A. niger como inóculo, a partir da Metodologia de Superfície de Resposta (MSR).

\section{MATERIAL E MÉTODOS}

\section{Materiais}

O micro-organismo utilizado foi o A. niger proveniente do Laboratório de Reaproveitamento de Resíduos Agroindustriais - LABRA da UESB campus de Itapetinga. $O$ farelo de cacau foi cedido como resíduo por uma agroindústria de beneficiamento de frutas localizada na região Sudoeste da Bahia, este foi seco em estufa com circulação de ar focado (SOLAB) a $70^{\circ} \mathrm{C}$ por 24 horas, e triturado em moinho tipo Wiley na granulométrica aproximada de $2 \mathrm{~mm}$ (SANTOS et al. 2011).

\section{Obtenção da solução de esporos}

$\mathrm{O} A$. niger foi inoculado em ágar-batata-dextrose (Himedia pH 5,02) por sete dias a $35^{\circ} \mathrm{C}$. A cultura esporulada foi suspensa em solução de Tween 80 VETEC a $0,01 \%$, onde foi efetuada a contagem do número de esporos em suspensão utilizando câmara de Neubauer com auxilio do microscópio binocular (Bioval L1000)

\section{Fermentação em estado sólido}

As fermentações foram realizadas em Erlenmeyers contendo $10 \mathrm{~g}$ de resíduo, com a adição de $10^{8}$ esporos por grama de substrato seco. Foram adicionados volumes de água destilada estéril até os seguintes valores de atividade de água aproximada de $0,963,0,976$ e 0,983 . Os cultivos foram conduzidos a $30^{\circ} \mathrm{C}$ em estufa bacteriológica, com o tempo fermentativo de 24, 72 e 120 horas de incubação (SL 101 SOLAB).

\section{Extração dos compostos enzimáticos}

Após o processo fermentativo, foram adicionados à biomassa $50 \mathrm{~mL}$ de solução tampão citrato de sódio (VETEC) com o pH 4,8 a $50 \mathrm{mM}$. Logo após este processo, esse extrato enzimático foi recolhido e centrifugado a $1.000 \mathrm{rpm}$ por 10 minutos em centrifuga e o sobrenadante foi aproveitado (CETRIBIO modelo 80-2B).

\section{Determinação da atividade de CMCase}

No tubo contendo o ensaio reacional foram adicionados $0,5 \mathrm{~mL}$ de solução tampão de citrato de sódio com o pH 4,8 a $50 \mathrm{mM}, 0,5 \mathrm{~mL}$ de extrato enzimático e $0,5 \mathrm{~mL}$ de CMC (carboxilmetilcelulose a $2 \% \mathrm{p} / \mathrm{v}$ ). No controle, foram adicionados $0,5 \mathrm{~mL}$ da solução tampão e $0,5 \mathrm{~mL}$ de extrato enzimático, enquanto que o branco da análise continha $0,5 \mathrm{~mL}$ de solução de ácido 3,5- dinitrosalicílico (DNS) e 0,5 
$\mathrm{mL}$ de solução tampão. Todas as amostras foram incubadas em estufa bacteriológica (SOLAB SL 101) a $50^{\circ} \mathrm{C}$ por 10 minutos, posteriormente, a reação foi interrompida com a adição de $0,5 \mathrm{~mL}$ DNS. Todos os tubos foram levados ao banho-maria contendo água fervente por 5 minutos, logo após foram adicionados 6,5 mL de água destilada para posterior medição de absorbância a $540 \mathrm{~nm}$ realizada em espectrofotômetro BEL Photonics 2000 UV (GHose, 1987).

Determinação da atividade do complexo FPase

Foram adicionados $1,0 \mathrm{~mL}$ de solução tampão de citrato de sódio com o pH 4,8 a $50 \mathrm{mM}, 0,5 \mathrm{~mL}$ de extrato enzimático e uma tira de papel filtro (1 x $6 \mathrm{~cm} \mathrm{n}{ }^{\circ} 1$ Whatman), no controle na reação foram adicionados $1,0 \mathrm{~mL}$ da mesma solução tampão e $0,5 \mathrm{~mL}$ de extrato enzimático, enquanto o controle do substrato foram adicionados $1,5 \mathrm{~mL}$ de solução tampão e uma tira de papel filtro. Todos os tubos foram levados ao banho-maria contendo água fervente por 5 minutos, logo após foram adicionados 20,0 mL deágua destilada para posterior medição de absorbância a $540 \mathrm{~nm}$ realizada em espectrofotômetro BEL Photonics 2000 UV (GHose, 1987).

\section{Determinação da atividade de Xilanase}

A atividade da enzima xilanase foi determinada segundo Miller (1959). A reação consiste na mistura contendo $10 \mathrm{~mL}$ de sobrenadante da cultura (extrato enzimático), 1,0 mL de solução de 1\% de xilana (Sigma) em 0,05 M de tampão acetato $\mathrm{pH}$ 5 ,0, e $2 \mathrm{~mL}$ da solução de DNS. As amostras foram incubadas a $50^{\circ} \mathrm{C}$ por 30 minutos e o sistema enzima-substrato foi agitado periodicamente para manter a xilana em suspensão. As leituras das absorbâncias de cada ensaio foram efetuadas em 500 nm (GOKHALE, 1986)

\section{Curva de calibração}

A curva padrão para a CMCase e a FPase foi construída a partir da determinação de glicose nas concentrações de 0,2 a 2,0 g/L pelo método do DNS (Miller, 1959). Para a Xilanase a curva foi construída a partir da determinação de 0,1 a $2 \mu \mathrm{mol}$ de xilose produzida por minuto. A unidade de atividade enzimática (U) foi definida como a quantidade de enzima capaz deliberar $1 \mu$ mol de açúcares redutores, por minuto a $50^{\circ} \mathrm{C}$, onde a atividade enzimática expressa em $\mathrm{U} / \mathrm{mL}$. A absorbância foi medida no espectrofotômetro a $540 \mathrm{~nm}$.

\section{Analise estatística}

O planejamento fatorial $2^{2}$ completo, em dois níveis $(-1$ e +1), envolvendo as variáveis indepen- dentes citadas, contou ainda com 3 ensaios sob as condições dos pontos centrais (nível zero) para o cálculo de resíduos e erro padrão. Assim, o planejamento fatorial consistiu em 18 ensaios e os valores das variáveis estudadas estão descritos na Tabela 1. Os experimentos do planejamento experimental foram realizados em triplicata e as variáveis resposta (dependentes) analisadas foram as atividades enzimáticas da CMCase, FPase e Xilanase.

Tabela 1 - Matriz dos ensaios para o planejamento fatorial $2^{2}$ completo.

\begin{tabular}{ccc}
\hline Ensaio & Tempo de fermentação $(\mathrm{h})$ & $\mathrm{a}_{\mathrm{w}}$ \\
\hline 1 & $24(-1)$ & $0,983(-1)$ \\
2 & $24(-1)$ & $0,983(-1)$ \\
3 & $120(1)$ & $0,983(-1)$ \\
4 & $120(1)$ & $0,983(-1)$ \\
5 & $24(-1)$ & $0,983(1)$ \\
6 & $24(-1)$ & $0,983(1)$ \\
7 & $120(1)$ & $0,983(1)$ \\
8 & $120(1)$ & $0,983(1)$ \\
9 & $72(0)$ & $0,983(-1)$ \\
10 & $72(0)$ & $0,976(0)$ \\
11 & $24(-1)$ & $0,976(0)$ \\
12 & $120(1)$ & $0,976(0)$ \\
13 & $72(0)$ & $0,976(0)$ \\
14 & $72(0)$ & $0,976(0)$ \\
15 & $72(0)$ & $0,976(0)$ \\
16 & $72(0)$ & $0,976(0)$ \\
17 & $72(0)$ & $0,976(0)$ \\
18 & $72(0)$ & $0,976(0)$ \\
\hline
\end{tabular}

A análise de variância (ANOVA) para os mode-los foi realizada e a importância do modelo foi examinada pelo teste estatístico de Fisher (teste F) através do teste de diferenças significativas entre as fontes de variação nos resultados experimentais, ou seja, a significância da regressão (SOR), o falta de ajuste (LOF) e o coeficiente de determinação múltipla $\left(\mathrm{R}^{2}\right)$.

\section{RESULTADOS E DISCUSSÃO}

Uma vez que esses modelos de segunda ordem não foram aceitos pelos testes estatísticos, então esses foram modificados através da eliminação de termos até que as condições estabelecidas foram cumpridas. Os fatores que não apresentaram diferenças significativas de 10\% foram agrupados no termo do erro e um novo modelo foi reduzido através da análise de regressão. Na Tabela 2 são apresentados os resultados experimentais quantificados durante as análises, utilizados para a modelagem estática matemática.

Na Tabela 3 são apresentados os resultados da ANOVA para esses modelos reduzidos. Os dados da Tabela 2 indicam que todos os modelos são estatisticamente significativos ( $\mathrm{F}>$ valor crítico, $\mathrm{P}<$ $0,05)$, esses resultados podem ser através do valor dos coeficientes de determinação múltipla $\left(R^{2}\right)$ que foram superiores a 0,70 para todas as enzimas. 
Tabela 2 - Valores experimentais das atividades das enzimas CMCase, FPase, Xilanase.

\begin{tabular}{ccccc}
\hline Tempo de fermentação $(\mathrm{h})$ & $\mathrm{a}_{\mathrm{w}}$ & CMCase U/mL & FPase U/mL & Xilanase U/mL \\
\hline $24(-1)$ & $0,963(-1)$ & 6,528818 & 3,320899 & 3,793004 \\
$24(-1)$ & $0,963(-1)$ & 5,698797 & 1,481393 & 2,768156 \\
$120(1)$ & $0,963(-1)$ & 8,345891 & 4,061188 & 5,799998 \\
$120(1)$ & $0,963(-1)$ & 6,753148 & 2,827373 & 5,180819 \\
$24(-1)$ & $0,983(1)$ & 6,506385 & 3,276033 & 9,237509 \\
$24(-1)$ & $0,983(1)$ & 5,698797 & 3,163868 & 2,960315 \\
$120(1)$ & $0,983(1)$ & 4,868776 & 1,728156 & 2,362487 \\
$120(1)$ & $0,983(1)$ & 2,378713 & 2,535744 & 1,529798 \\
$72(0)$ & $0,963(-1)$ & 6,865313 & 4,779044 & 6,568634 \\
$72(0)$ & $0,983(1)$ & 6,080158 & 4,352817 & 7,700237 \\
$24(-1)$ & $0,976(0)$ & 5,967993 & 4,82391 & 9,344264 \\
$120(1)$ & $0,976(0)$ & 5,339869 & 4,509848 & 6,355124 \\
$72(0)$ & $0,976(0)$ & 8,996448 & 4,173353 & 9,835337 \\
$72(0)$ & $0,976(0)$ & 9,691871 & 4,307951 & 7,871045 \\
$72(0)$ & $0,976(0)$ & 14,425234 & 7,740201 & 11,863682 \\
$72(0)$ & $0,976(0)$ & 14,178471 & 7,448571 & 10,091549 \\
$72(0)$ & $0,976(0)$ & 14,380368 & 7,829932 & 11,39396 \\
$72(0)$ & $0,976(0)$ & 14,268203 & 7,785066 & 10,646675 \\
\hline
\end{tabular}

Tabela 3 - Modelo de Superfície de Resposta obtido através da ANOVA.

\begin{tabular}{|c|c|c|c|c|c|}
\hline & DF & SS & MS & F & $\mathrm{P}$ \\
\hline & CMCase & & & & \\
\hline Modelo & 3 & 3591,0932 & 1197,0311 & 0,8617 & 0,0048 \\
\hline Residual & 14 & 19448,9068 & 1389,2076 & & \\
\hline Total & 18 & 23040,0000 & 1355,2941 & & \\
\hline Erro padrão & 23,4550 & & & & \\
\hline \multirow[t]{2}{*}{$\mathrm{R}^{2}$} & 0,8453 & & & & \\
\hline & FPase & & & & \\
\hline Modelo & 3 & 93356,6614 & 23339,1653 & 0,0091 & 0,0049 \\
\hline Residual & 14 & 22995,3386 & 1642,5242 & & \\
\hline Total & 18 & 116352,0000 & 6464,0000 & & \\
\hline Erro padrão & 35,7462 & & & & \\
\hline \multirow[t]{2}{*}{$\mathrm{R}^{2}$} & 0,7964 & & & & \\
\hline & Xilanase & & & & \\
\hline Modelo & 3 & 594,6474 & 198,2158 & 0,1236 & 0,0034 \\
\hline Residual & 14 & 22445,3526 & 1603,2395 & & \\
\hline Total & 18 & 23040,0000 & 1355,2941 & & \\
\hline Erro padrão & 38,7582 & & & & \\
\hline $\mathrm{R}^{2}$ & 0,8793 & & & & \\
\hline
\end{tabular}

DF: Graus de Liberdade; SS: Soma dos Quadrados; MS: Media dos Quadrados; F: Valores Teste F; P: Significância Estatística.

Os modelos reduzidos podem ser descritos pelas equações (1), (2) e (3), em termos de valores não codificados. Onde AC1, AC2 e AC3 estão para o ativo da CMCase, FPase exilanase, respectivamente.

$$
\begin{aligned}
& \text { AC1 }=4,847 X_{1}-0,0493 X_{1}^{2}+0,326 X_{2}-0,00230 X_{2}^{2}(1) \\
& \text { AC2 }=0,179 X_{1}-0,00125 X_{1}^{2}+2,911 X_{2}-0,0292 X_{2}^{2}(2) \\
& \text { AC3 }=4,882 X_{1}-0,0489 X_{1}^{2}+0,271 X_{2}-0,00198 X_{2}^{2}(2)
\end{aligned}
$$

De acordo com Granato et al. (2010), para validar o modelo ajustado os valores otimizados das variáveis independentes $\left(\mathrm{X}_{1}\right.$ e $\left.\mathrm{X}_{2}\right)$ deve ser usado no procedimento inicial $l$, a fim de verificar o poder de previsão dos modelos desenvolvidos por meio da comparação de dados teóricos previsto para o modelo experimental. Neste trabalho $X_{1}$ e $X_{2}$ representam, respectivamente, atividade de água e tempo.

A modelagem matemática de processos fermentativos pode ser definida como a tentativa de representar, por equações matemáticas, os balanços de massa, associados às transformações bioquímicas que ocorrem no processo e às velocidades com que essas transformações se processam. Estes modelos foram usados para determinar a superfície de resposta, relacionando as duas variáveis independentes, como demonstradas nas Figuras 1, 2 e 3. 


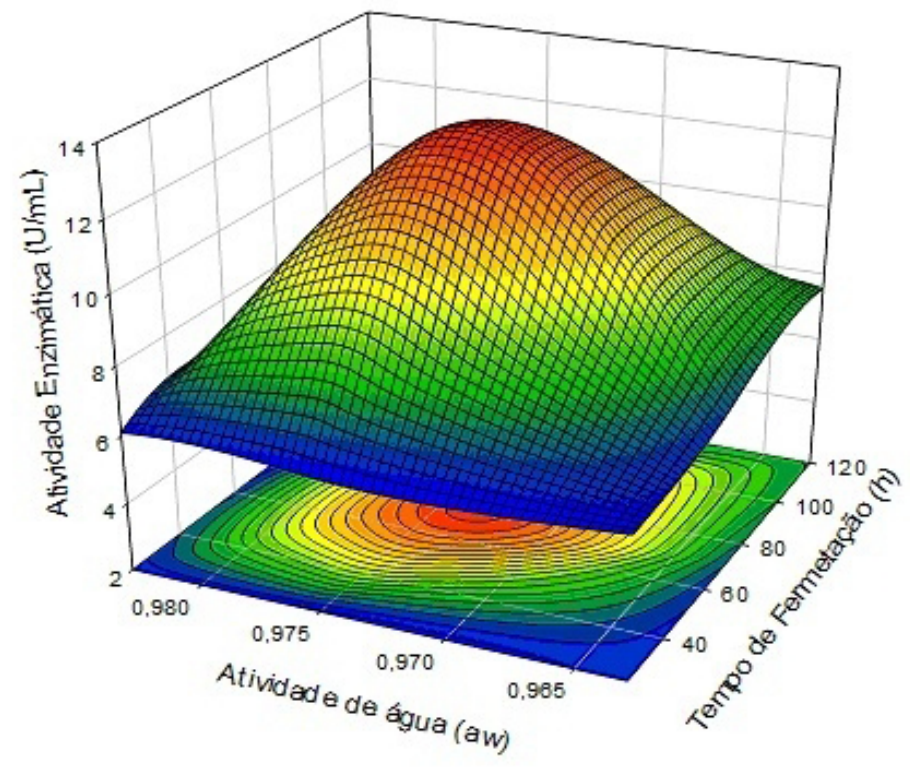

Fig. 1-Efeito do tempo de fermentaçãoe atividade de água sobre a atividade da endoglucanase (CMCase).

Fig. 2-Efeito do tempo de fermentação eatividade de água sobre a atividade do complexo endoglucanase e exoglucanase (FPase).
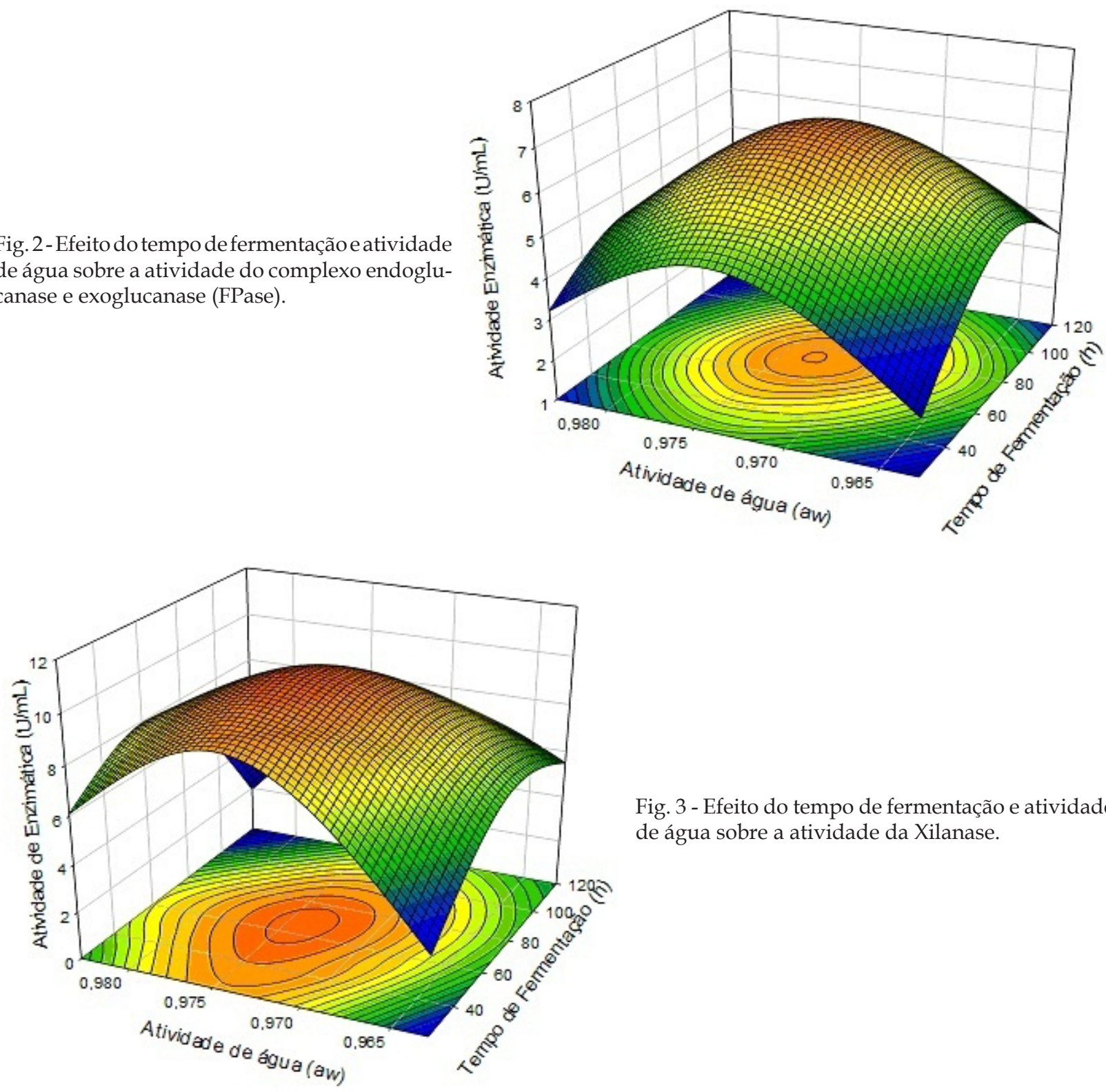

Fig. 3 - Efeito do tempo de fermentação e atividade de água sobre a atividade da Xilanase. 
Tabela 4 - Efeito da atividade de água com tempo de fermentação.

\begin{tabular}{lcrr}
\hline & $\begin{array}{c}\text { Tempo de } \\
\text { fermentação }(\mathrm{h})\end{array}$ & $\mathrm{a}_{\mathrm{w}}$ & \multicolumn{1}{c}{$\mathrm{U} / \mathrm{mL}$} \\
\hline CMCase & 70,07 & 0,972 & $14,18 \mathrm{U} / \mathrm{mL}$ \\
FPase & 80,56 & 0,974 & $7,51 \mathrm{U} / \mathrm{mL}$ \\
Xilanase & 64,24 & 0,971 & $11,86 \mathrm{U} / \mathrm{mL}$ \\
\hline
\end{tabular}

O efeito da umidade e do tempo de fermentação sobre as atividades das enzimas estudadas estão demonstradas nas Figuras 1, 2 e3. Os valores ótimos de tempo e atividade de água para a CMCase, FPase e Xilanase estão relacionados na Tabela 4.

Constatou-se que o tempo de fermentação influenciou significativamente a produção enzimática onde o tempo médio foi entre 60 a $80 \mathrm{~h}$ para todas as atividades enzimáticas. Uma hipótese para esta decorrência seria que a presença dos nutrientes dispersos ao longo da fermentação pode ter contribuído para o crescimento do micro-organismo, e o decaimento destes nutrientes ao longo do tempo pode ter interferido na atividade enzimática e, com isso, houve o decaimento da produção microbiana e, consequentemente, a produção enzimática.

O teor de água é um fator bastante significativo no processo fermentativo. Elevada atividade de água causa a diminuição da porosidade do substrato, diminuindo assim a troca de gases. Por outro lado, uma baixa atividade de água pode acarretar diminuição do crescimento microbiano e consequente menor produção de enzima (MAHANTA et al., 2008; SANTOS et al. 2012). O que se pode notar é que a umidade aproximada de 0,97 foi a ideal para a obtenção das enzimas aqui estudadas. Nas demais atividades de água estudadas, 0,963 e 0,983, houve a diminuição da atuação fúngica e pode estar relacionado com a inibição do fungo, marcado pela extrapolação do nível de água ideal para o desenvolvimento da linhagem selecionada no caso de $0,983 \mathrm{a}_{\mathrm{w}^{\prime}}$ ou a baixa atividade de água necessária para que o fungo se desenvolva como pode ter ocorrido em 0,963 . Estas duas condições podem ter influenciado no metabolismo responsável pela produção da enzima.
Seguea Tabela 5 comparativa dos resultados para as enzimas aqui estudadas, valores quantificados por pesquisadores atuais.

Em todos os trabalhos citados anteriormente, os tempos de incubação variaram de 7 a 10 dias, bem maiores que aqueles utilizados neste trabalho. Podese perceber valores superiores nas atividades enzimáticas em trabalhos com suplemento de carbono e nitrogênio no que se diz respeito a CMCase, porém, é possível notar que no experimento aqui realizado as atividades de FPase e Xilanase são superiores a aqueles apresentados com outros substratos. É importante ressaltar que não foi utilizado nenhum tipo de indutor, suprimento, além do farelo de cacau in natura, ou pré-hidrólise do substrato, demonstrando assim que as enzimas são constitutivas.

\section{CONCLUSÕES}

Utilizar o farelo de cacau como substrato de crescimento para o Aspergilus niger é promissor para a produção deenzimas celulásicas, com destaque para a CMCase, na condição de 0,972 de atividade deágua e incubação por 70,07 horas de fermentação. Futuramente deve ser feita a avaliação desses ensaios com outras fontes de carbono (resíduos agroindustriais), bem como a utilização de novas espécies microbianas e o estudo de outras variáveis.

\section{AGRADECIMENTOS}

Os autores agradecem ao Conselho Nacional de Desenvolvimento Científico e Tecnológico (CNPq) pelas bolsas de ITI (Iniciação Tecnológica Industrial) concedidas e ao Banco do Nordeste (BNB) pelo apoio financeiro.

\section{REFERÊNCIAS}

ADSUL, M.G.; GHULE, J.E.; SINGH, R.; SHAIKH, H.; BASTAWDE, K.B.; GOKHALE, D.V.; VARMA, A.J. Polysaccharides from bagasse: applications in cellulase

Tabela 5 - Valores comparativos encontrados em demais pesquisas para enzimas lignolíticas.

\begin{tabular}{llllc}
\hline Autor & Enzima & Substrato & Micro-organismo & Atividade \\
\hline JANG;CHEN, 2003 & CMCase & CMCe sulfato de amônio, & Actinomicetos Streptomyces & $40,3 \mathrm{U} / \mathrm{mL}$ \\
GEORGE et al., 2001 & CMCase & ureia e peptona & Thermomonospora sp. & $8,5 \mathrm{U} / \mathrm{mL}$ \\
JORGENSEN; OLSSON, 2006 & FPase & Pinheiro & Penicilium brasilianum & $0,59 \mathrm{U} / \mathrm{mL}$ \\
ADSUL et al., 2004 & FPase & Bagaço de cana & Trichoderma viride & $0,4 \mathrm{U} / \mathrm{mL}$ \\
QINNGHE et al. 2004 & Xilanase & Sabugo de milho e aveia & Pleurotus ostreatus & $24,98 \mathrm{U} / \mathrm{mL}$ \\
SALES, 2010. & Xilanase & Cana-de-açúcar & Linhagens de Aspergillus & $9,00 \mathrm{U} / \mathrm{mL}$ \\
\hline
\end{tabular}


and xylanase production. Carbohydrate Polymers, v.57, n.1, p.67-72, 2004.

ARANTES, V.SADDLER, J.N. Access to cellulose limits the efficiency of enzymatic hydrolysis: the role of amorphogenesis. Biotechnology for Biofuels, v.3, n.4, p.1-11, 2010.

JANG, H.D.; CHEN, K.S. Production and characterization of thermostable cellulases from Streptomyces transformant T3-1. World Journal of Microbiology and Biotechnology, v.19, n.2, p.263-268, 2003.

JORGENSEN, H.; OLSSON, L. Production of cellulases by Penicillium brasilianum IBT 20888 - Effect of substrate on hydrolytic performance. Enzyme and Microbial Technology, v.38, n.3/4, p.381-390, 2006.

GEORGE, S.P.; AHMAD, A.; RAO, M.B. Studies on carboxymethyl cellulose produced by an alkalothermophilic actinomycete. Bioresource Technology, v.77, n.2, p.171-175, 2001.

GHOSE T.K. Measurement of cellulase activities. Pure and Applied Chemistry, v.59, n.1, p.257-268, 1987.

GRANATO, D.; RIBEIRO, J.C.B.; CASTRO, I.A.; MASSON. M.L. Sensory evaluation and physicochemical optimization of soy-based desserts using response surface methodology. Food Chemistry, v.121, p.899-906, 2010.

GOKHALE, D. U. Xylanase and betaxylosidase production by Aspergillus niger NCIM 1207. Biotechnology Letters, v.8, p.137138, 1986.

MAHANTA, N.; GUPTA, A.; KHARE, S. K. Production of protease and lipase by solvent tolerant Pseudomonas aeruginosa PseA in solid-state fermentation using Jatropha curcas seed cake as substrate. Bioresource Technology, v.99, n.1, p.1729-1735, 2008

MENEZES, G.D.G. Produção de poligalacturonase pela linhagem Aspergillus niger mutante 3T5B8 por fermentação semi-sólida em biorreatores de coluna. 2006. Dissertação (Mestrado) - Instituto de Tecnologia, Universidade Federal Rural do Rio de Janeiro, Rio de Janeiro, 2006.

MILLER, G.L. Use of dinitrosalicylic acid reagent for determination of reducing sugar. Analytical Chemistry, v.31, n.1, p.426-428, 1959.

QINNGHE, C.; XIAOYU, Y.; TIANGUI, N.; CHENG, J.; QIUGANG, M. The screening of culture condition and properties of xylanase by white-rot fungus Pleurotus ostreatus. Process Biochemistry, v.39, n.5, p.561-566, 2004.
PARK, Y.; KANG, S.; LEE, J.; HONG, S.; KIM, S. Xylanase production in solid state fermentation by Aspergillus niger mutant using statistical experimental designs. Applied Microbiology and Biotechnology, v.58, n.6, p.761-766, 2002.

PIRES, A.J.V.; VIEIRA, V.F.; SILVA, F.F.; VELOSO, C.M.; SOUZA, A.L.; OLIVEIRA, T.N.; SANTOS, C.L.; CARVALHO, G.G.P.; Níveis de Farelo de Cacau (Theobroma cacao) na alimentação de bovinos. Revista Electrónica de Veterinaria, v.1, n.2, 2005.

SALES, M.R.; MOURA, R.B.; PORTO, T.S.; MACEDO, G.R; PORTO, A.L.F. Variáveis que influenciam a produção de celulases e xilanase por espécies de Aspergillus. Pesquisa Agropecuária Brasileira, v.45, n.11, p.1290-1296, 2010.

SANTOS, T. C.; CAVALCANTI, I.S.; BONOMO, R.C.F.; SANTANA, N.B.; FRANCO, M. Optimization of productions of cellulolytic enzymes by Aspergillus niger using residue of mango a substrate. Ciência Rural, v.41, p.2210-2216, 2011.

SANTOS, T.C.; GOMES, D.P.P.; BONOMO, R.C.F.; FRANCO, M. Optimisation of solid state fermentation of potato peel for the production of cellulolytic enzymes. Food Chemistry, v.133, p.1299-1304, 2012.

SIMÕES, M.L.G.; TAUK-TORNISIELO, S.M. Comparação da técnica tradicional e do método turbidimétrico automatizado no cultivo em diferentes fontes de carbono de fungos filamentosos isolados de solo de área de caatinga. Holos Environment, v.5, n.2, p.94-103, 2005.

SILVEIRA, C.M.; FURLONG, E.B. Caracterização de compostos nitrogenados presentes em farelos fermentados em estado sólido. Ciência e Tecnologia de Alimentos, v.27, n.4, p.805-811, 2007.

SLIVINSKI, C.T. Produção, purificação parcial e caracterização bioquímica de glucoamilase de Aspergillus niger obtida por fermentação em estado sólido. 2007. Dissertação (Mestrado) - Universidade Estadual de Ponta Grossa, Ponta Grossa, 2007.

YANG, S.Q.; YAN, Q.J.; JIANG, Z.Q.; LI, L.T.; TIAN, H.M.; WANG, Y.Z. High-level of xylanase production by the thermophilic Paecilomyces themophila J18 on wheat straw in solid-state fermentation. Bioresource Technology, v.97, n.15, p.1794-1800, 2006.

Recebido em $4 / 8 / 11$

Aceito em 18/12/12 